\title{
Oil and the World Economy: Some Possible Futures
}

Michael Kumhof and Dirk Muir 


\title{
IMF Working Paper
}

Research Department

\section{Oil and the World Economy: Some Possible Futures \\ Prepared by Michael Kumhof and Dirk Muir}

Authorized for distribution by Douglas Laxton

October 2012

\section{This Working Paper should not be reported as representing the views of the IMF.} The views expressed in this Working Paper are those of the author(s) and do not necessarily represent those of the IMF or IMF policy. Working Papers describe research in progress by the author(s) and are published to elicit comments and to further debate.

\begin{abstract}
This paper, using a six-region DSGE model of the world economy, assesses the GDP and current account implications of permanent oil supply shocks hitting the world economy at an unspecified future date. For modest-sized shocks and conventional production technologies the effects are modest. But for larger shocks, for elasticities of substitution that decline as oil usage is reduced to a minimum, and for production functions in which oil acts as a critical enabler of technologies, GDP growth could drop significantly. Also, oil prices could become so high that smooth adjustment, as assumed in the model, may become very difficult.
\end{abstract}

JEL Classification Numbers:C11, C53, Q31, Q32

Keywords: Exhaustible resources; fossil fuels; oil depletion; Hubbert's Peak; externalities.

Author's E-Mail Address:mkumhof@imf.org; dmuir@imf.org 


\section{Contents}

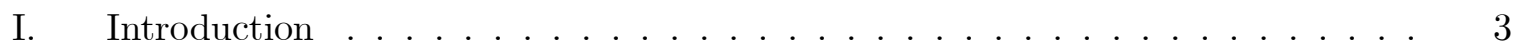

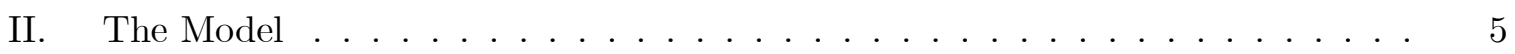

A. Oil Supply . . . . . . . . . . . . . . . . . . 6

B. Oil Demand . . . . . . . . . . . . . . . . . . 7

1. Baseline Scenario . . . . . . . . . . . . . . 7

2. Growing Elasticity Scenario . . . . . . . . . . . . . . . 7

3. Entropy Boundary and Falling Elasticity Scenarios . . . . . . . . 8

4. Technology Externality Scenario . . . . . . . . . . . . . . 9

C. World Oil Market Equilibrium . . . . . . . . . . . . . . . . . . 9

D. Calibration . . . . . . . . . . . . . . . . . . 9

III. Discussion of the Alternative Specifications . . . . . . . . . . . . . . . . . 10

A. Entropy Boundary and Falling Elasticity Scenarios _ . . . . . . . . . 10

1. Supply Limitations . . . . . . . . . . . . . . . . . . . . 11

2. Technical Substitutability . . . . . . . . . . . . . . 13

B. Growing Elasticity Scenario . . . . . . . . . . . . . . . . 14

C. Technology Externality Scenario . . . . . . . . . . . . . . . . . . 14

IV. Simulation Results . . . . . . . . . . . . . . . . . . . . . . . . 15

A. Baseline Scenario . . . . . . . . . . . . . . . . . 15

B. Growing Elasticity Scenario . . . . . . . . . . . . . . . . 16

C. Entropy Boundary Scenario and Falling Elasticity Scenario . . . . . . . . 17

D. Technology Externality Scenario . . . . . . . . . . . . . . . . 18

E. Larger Shock Scenario . . . . . . . . . . . . . . . . . . . . . . . . . . . . . . .

F. Combined Downside Scenarios . . . . . . . . . . . . . . . . . . 19

G. Combined Downside and Growing Elasticity Scenario . . . . . . . . . 20

H. The Assumption of Unitary Income Elasticity . . . . . . . . . . . . . . . 20

I. The Assumption of Smooth Reallocation . . . . . . . . . . . . . . . . 20

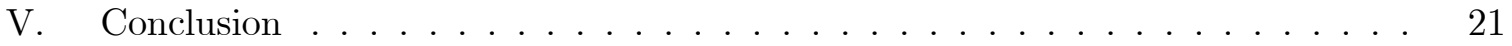

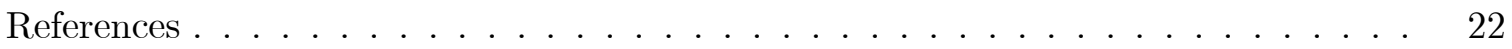

Figures

1. World Crude Oil Production (in million barrels per day) . . . . . . . . . . . . 24

2. The Entropy Boundary in Factor Space . . . . . . . . . . . . . . . . 24

3. Baseline Scenario . . . . . . . . . . . . . . . . . . . 25

4. Growing Elasticity Scenario . . . . . . . . . . . . . . 26

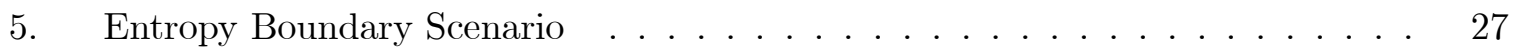

6. Falling Elasticity Scenario . . . . . . . . . . . . . . . . . 28

7. Technology Externality and Larger Shock Scenarios . . . . . . . . . . . . . . 29

8. Combined Downside and Growing Elasticity Scenario . . . . . . . . . . . 30 


\section{Introduction}

Over the past decade the world economy has experienced a persistent increase in oil prices. While part of this may have been due to continued rapid demand growth in emerging markets, stagnant supply also played a major role. Figure 1 shows the sequence of downward shifts in the trend growth rate of world oil production since the late $1960 \mathrm{~s} .{ }^{1}$ The latest trend break occurred in late 2005, when the average growth rate of 1.8 percent per annum of the 1981-2005 period could no longer be sustained, and production entered a fluctuating plateau that it has maintained ever since.

This paper attempts to analyze the implications of potential further downward shifts in the growth rate of world oil production for the world economy. ${ }^{2}$ The focus is on GDP, current account imbalances, and oil prices. We use simulation analysis based on the IMF's Global Integrated Monetary and Fiscal Model (GIMF), a six-region dynamic general equilibrium model of the world economy that is frequently used at the IMF for policy and scenario analysis. In GIMF oil is a separate and exhaustible factor of production in addition to capital and labor, with demand and supply elasticities that are empirically based and very low.

The analysis begins with a baseline scenario in which the economy experiences a negative oil supply shock. ${ }^{3}$ This scenario makes two important assumptions. First, the reduction in the trend growth rate of world oil output, while highly persistent, is relatively modest at 1 percentage point. Second, a conventional macroeconomic model, with oil entering the economy's production and consumption technologies as part of simple constant-elasticity-of-substitution (CES) aggregators, is adequate under conditions of increasing oil scarcity. We find that under those two assumptions oil scarcity may not become a major constraint on global growth, nor would it dramatically worsen current account imbalances. We also find that if long-run price elasticities of oil demand are increasing functions of the oil price, specifically if they double or triple following a permanent doubling of the real price of oil, then the effects on growth and current account imbalances are even smaller. We refer to this as the Growing Elasticity Scenario. We then modify the Baseline Scenario in a number of ways that are based on the scientific literature. We find that the adverse effects can become much larger under the following downside scenarios:

(1) The Entropy Boundary and Falling Elasticity Scenarios: The price elasticity of oil demand decreases rather than increases under conditions of increasing oil scarcity. The reason is that the substitutability between oil and other factors of production is limited by a factor space boundary such that regions of the factor space with very low oil use per unit of output are not accessible, because a minimum oil input is required per unit of output to offset the effects of entropy. We present two separate scenarios to represent this case, one with an explicit boundary in factor space, and a reduced form alternative where

\footnotetext{
${ }^{1}$ Figure 1 shows production of crude oil. Other commonly used aggregates also include natural gas liquids and other liquids.

${ }^{2}$ The paper represents a further development of the analysis contained in chapter 3 of the April 2011 IMF World Economic Outlook (Helbling and others (2011)).

${ }^{3}$ In the econmics literature a "shock" is a sudden and unanticipated change in one of the economy's driving forces, in this case the growth rate of world oil supply.
} 
the price elasticity of oil demand is an increasing function of oil availability. A more detailed discussion in presented in Section III.A.

(2) The Technology Externality Scenario: The output contribution of oil is higher than indicated by its cost share. We start from the premise that the availability of oil is a critical precondition for the continued viability of many key technologies that contain materials or use fuels derived from oil. In addition, we assume that this benefit of oil, like technology, is external, and is therefore not captured mainly by the producers of oil, but rather by all factors of production. This means that these productivity effects of oil are, unlike oil's direct contribution to output, not fully reflected in cost shares. A more detailed discussion in presented in Section III.C.

(3) The Larger Shock Scenario: The reduction in the growth rate of world oil production is much larger than in the baseline, at 4 percentage points rather than 1 percentage point, in line with several recent forecasts in the scientific literature.

These downside simulations, alone but especially in combination, can lead to a reduction in the growth rate of world GDP of several percentage points. But more ominously, even when combined with the Growing Elasticity Scenario, they predict oil prices of such magnitude that a smooth adjustment, as assumed in the model, cannot be taken for granted.

This points to important avenues for future research. Most importantly, we suggest that a multidisciplinary approach to modeling, which better represents the dependence of production technologies on physical processes, would be very useful.

This paper, based on empirical evidence, pays serious attention to the view that geology will at some point in the not-too-distant future start to constrain world oil production, but without taking a stand on the precise year in which this will happen. According to the geological view oil reserves are ultimately finite, easy-to-access oil is produced first, and therefore oil must become harder and more expensive to produce as the cumulative amount of oil already produced grows. According to many scientists that advocate this view, the recently observed stagnant oil production in the face of persistent and large oil price increases is a sign that physical scarcity of oil is already here, or at least imminent, and that it must eventually overwhelm the stimulative effects of higher oil prices on oil production. Furthermore they state, on the basis of extensive studies of alternative technologies and resources, that suitable substitutes for oil simply do not exist on the required scale and over the required horizon ${ }^{4}$, and that technologies to improve oil recovery from existing fields, and to economize on oil use, must eventually run into limits dictated by the laws of thermodynamics, specifically entropy. This view of oil supply traces its origins back to the work of M. King Hubbert (1956), a geoscientist who in 1956 correctly predicted that U.S. oil output would peak in 1970. It is discussed in a study produced for the U.S. Department of Energy ${ }^{5}$, Hirsch and others (2005), and in a subsequent book, Hirsch and others (2010). The most thorough scientific research

\footnotetext{
${ }^{4}$ As we will discuss, existing technologies may permit significant substitution away from oil towards gas and coal once oil prices reach very high levels. This may well delay the moment at which oil supply problems start to have serious effects, but probably by years rather than decades.

${ }^{5}$ Other studies by official U.S. agencies that have warned about this issue include United States Government Accountability Office (2007) and United States Joint Forces Command (2010).
} 
available on this topic is UK Energy Research Centre (2009), which is succinctly summarized in Sorrell and others (2010). Based on a wealth of geological and engineering evidence, these authors conclude that there is a significant risk of a peak in conventional oil production before 2020, with an inexorable decline thereafter. Given that this still allows for a wide range of possible dates for the next major trend break, we will not be specific concerning the year at which the shock hits the world economy in our simulations.

Benes and others (2012) provide additional empirical support for our concern with the future of global oil production. Their paper reconciles the geological view of oil with the economic/technological view, whereby higher oil prices must eventually have a decisive effect on production by stimulating greater use of technology. Their nonlinear econometric model represents the geological view by incorporating the Hubbert linearization specification of Deffeyes (2005) into its oil supply equation, while representing the economic/technological view by a conventional price sensitivity of oil supply. The other estimating equations, for oil demand and output growth, are standard in the literature. This model performs far better than competing models in forecasting oil prices and oil output out of sample, and the main reason is the geological, price-insensitive component of supply, which captures the underlying trends in both quantities and prices. The model's point forecast is for a near doubling of the real price of oil over the coming decade, with wide error bands that reflect sharply differing judgments on ultimately recoverable reserves, and on future price elasticities of oil demand and supply. The estimated long-run price elasticity of oil demand equals 0.08 , while the estimated long-run price elasticity of oil supply, under the assumption that significant spare capacity will not be available in the future, equals 0.02 . Finally, a fairly small reduction in the world economy's ability to draw on spare capacity could take a full percentage point off world growth.

The spirit of our exercise is to systematically think through various possibilities for how future scarcity of oil could affect global output and current account imbalances. At this point there are many details, like the future behavior of price elasticities, that we simply do not know enough about, and clearly this calls for much more empirical work. But any empirical work will inevitably analyze the data through the interpretive lens of some theoretical modeling framework, whether it acknowledges this or not. A key goal of this paper is therefore to expand that modeling framework in ways that allow for plausible additional possibilities. In other words, we attempt to widen the interpretive lense.

The rest of the paper is organized as follows. Section II presents the relevant details of the model and its calibration. Section III discusses the rationales for the main alternative scenarios in more detail. Section IV presents simulation results for the baseline and alternative scenarios. Section V concludes.

\section{The Model}

The IMF's Global Integrated Monetary and Fiscal Model (GIMF) is fully documented in Kumhof and others (2010). GIMF includes several features found to be important for replicating real-world behavior, including finite planning horizons for households and firms, gradual adjustment of prices, nominal wages, consumption, investment and imports to unexpected changes, a financial system where losses constrain borrowers' future activity 
through higher financing costs, and a fully specified fiscal sector. The version used here has six economic regions - oil exporters, the United States, the euro area, Japan, emerging Asia, and remaining countries. For reporting purposes these will be aggregated as "Oil Exporters", "USA and the Euro Area" and "Rest of the World". All regions are assumed to have flexible exchange rates.

In GIMF oil is a third factor production, in addition to capital and labor, and a second factor in final consumption, in addition to goods and services. The price and availability of oil therefore influence production as well as consumption possibilities. The updated version of GIMF used in this paper extends the theoretical framework of Kumhof and others (2010), by allowing for elasticities of substitution between oil and other factors that can rise with the oil price or fall with the available quantity of oil, entropy boundaries in production and consumption that put limits on the substitution away from oil, and technology externalities from oil in production that raise the output contribution of oil, and that give oil supply shocks aspects of technology shocks. In all equations presented below, real variables are detrended by the level of world technology, which grows at an exogenous and constant rate of 1.5 percent per annum. Steady state values are denoted by a bar above the respective variable.

\section{A. Oil Supply}

Each region's supply of oil is exogenous ${ }^{6}$, except for a quantitatively small elasticity of oil supply with respect to the oil price. It is given by

$$
\log \left(O_{t}^{\text {sup }}\right)=\log \left(O_{t}^{\text {sup* }}\right)+\epsilon_{s} \log \left(p_{t}^{O, \text { avg }} / \bar{p}^{O}\right)
$$

where $p_{t}^{O, a v g}=\left(p_{t}^{O}\left(p_{t-1}^{O, a v g}\right)^{3}\right)^{\frac{1}{4}}$, where $O_{t}^{\text {sup }}$ is an individual region's oil production and $p_{t}^{O}$ is the oil price in local currency. In the initial steady state of the economy the exogenous part of oil supply $\bar{O}^{\text {sup* }}$ is assumed to be a constant when normalized by trend growth. In other words, oil output prior to the simulated supply shock grows at the same trend rate as output. The simulations will subject $O_{t}^{\text {sup* }}$ to exogenous shocks whereby oil output grows, for three decades, at a significantly lower rate than the historic trend growth rate.

The long-run price elasticity of oil supply is given by $\epsilon_{s}$. Specifically, equation (1) states that the output of oil rises by $\epsilon_{s}$ percent for a one percent deviation of the lagged moving average of oil prices $p_{t-4}^{O, a v g}$ from the long-run steady state oil price $\bar{p}^{O}$. The particular parameterization of the moving average expression adopted here implies that the average oil price $p_{t}^{O, a v g}$ starts to fully reflect permanent changes in the actual oil price $p_{t}^{O}$ after a period of around 5 years. The moving average term enters with a four-year lag because we are interested in capturing the effects of higher oil prices on exploration activity and new field development, and it is well known in the industry that the lead time for bringing new capacity online equals four years or more. It is possible to also introduce a responsiveness of output to the current oil price, which corresponds to oil producers utilizing existing

\footnotetext{
${ }^{6}$ In economic jargon, oil is an endowment.
} 
spare capacity ${ }^{7}$ when prices are favorable. However, we decided not to pursue this, because persistently high spare capacity would be very unlikely to occur under the scenarios we study here.

\section{B. Oil Demand}

\section{Baseline Scenario}

The economy has three sectors that require oil, the nontradables (superscript $N$ ) and tradables (superscript $T$ ) manufacturing sectors, and the consumption (superscript $C$ ) sector. We use the general notation $J$ for sectors $J \in\{N, T, C\}$. The baseline production function (and similarly the consumption aggregator) is a CES aggregate over oil $O_{t}^{J}$ and a Cobb-Douglas composite $M_{t}^{J}$ consisting of capital $K_{t}^{J}$ and labor $L_{t}^{J}$, with a quasi-share parameter for oil of $\eta^{J}$ and an elasticity of substitution, or long-run price elasticity of oil demand, of $\epsilon_{d}$. The latter is for simplicity assumed to be equal across sectors. Finally, an adjustment cost $G_{O, t}^{J}$ makes it costly to rapidly vary the use of oil in response to shocks. This has the effect of making the short-run price elasticity of oil demand lower than the long-run price elasticity $\epsilon_{d}$. The production function for the Baseline Scenario is given by

$$
\begin{gathered}
Z_{t}^{J}=\left(\left(1-\eta^{J}\right)^{\frac{1}{\epsilon_{d}}}\left(M_{t}^{J}\right)^{\frac{\epsilon_{d}-1}{\epsilon_{d}}}+\left(\eta^{J}\right)^{\frac{1}{\epsilon_{d}}}\left(O_{t}^{J}\left(1-G_{O, t}^{J}\right)\right)^{\frac{\epsilon_{d}-1}{\epsilon_{d}}}\right)^{\frac{\epsilon_{d}}{\epsilon_{d}-1}} \\
M_{t}^{J}=\left(K_{t}^{J}\right)^{1-\alpha}\left(L_{t}^{J}\right)^{\alpha} \\
G_{O, t}^{J}=\frac{\phi_{O}}{2}\left(\frac{O_{t}^{J}-O_{t-1}^{J}}{O_{t-1}^{J}}\right)^{2} .
\end{gathered}
$$

\section{Growing Elasticity Scenario}

Here we assume the same specification as in (2), but with the long-run elasticity $\epsilon_{d}$ replaced by a time varying $\epsilon_{d, t}$ that is given by

$$
\log \left(\epsilon_{d, t}\right)=\log \left(\epsilon_{d}\right)+\epsilon_{\epsilon}^{p} \log \left(p_{t}^{O, a v g} / \bar{p}^{O}\right) .
$$

The parameter $\epsilon_{\epsilon}^{p}$, which equals 0 in the Baseline Scenario, and 1 or 2 in the Growing Elasticity Scenario, is the elasticity of the price elasticity of oil demand with respect to a moving average of oil prices. For $\epsilon_{\epsilon}^{p}=1$, a doubling of the oil price relative to its initial steady state leads to a doubling of the long-run price elasticity of oil demand.

\footnotetext{
${ }^{7}$ Spare capacity is the amount of oil that producers could technically bring to market immediately if prices (and politics) justified it. The evidence shows that when officially reported spare capacity drops below 2 million barrels per day, oil prices start to increase sharply. In other words at that level, which was reached both in 2008 and recently, the price elasticity of oil production drops sharply.
} 


\section{Entropy Boundary and Falling Elasticity Scenarios}

In this alternative specification the production function takes the form

$$
Z_{t}^{J}=\left(\left(1-\eta^{J}\right)^{\frac{1}{\epsilon_{d}^{J}}}\left(M_{t}^{J}\right)^{\frac{\epsilon_{d}^{J}-1}{\epsilon_{d}^{J}}}+\left(\eta^{J}\right)^{\frac{1}{\epsilon_{d}^{J}}}\left(O_{t}^{J}\left(1-G_{O, t}^{J}\right)-\beta \frac{\bar{O}^{J}}{\bar{M}^{J}} \tilde{M}_{t}^{J}\right)^{\frac{\epsilon_{d}^{J}-1}{\epsilon_{d}^{J}}}\right)^{\frac{\epsilon_{d}^{J}}{\epsilon_{d}^{J}-1}}
$$

The Stone-Geary term $-\beta\left(\bar{O}^{J} / \bar{M}^{J}\right) \tilde{M}_{t}^{J}$ represents the entropy boundary, with $\left(\bar{O}^{J} / \bar{M}^{J}\right)$ denoting the initial steady state ratio of oil inputs to other factor inputs, $\beta$ denoting the proximity of the entropy boundary to that ratio, and $\tilde{M}_{t}^{J}$ denoting the macroeconomic scale of production as measured by the capital-labor bundle. We assume that producers take $\tilde{M}_{t}^{J}$ to be exogenous when deciding on their optimal input use, meaning that an individual agent acts as though he cannot affect the overall scale of production, while in equilibrium we have $\tilde{M}_{t}^{J}=M_{t}^{J}$. With $\beta=0$ this model reverts to the standard specification (2), but as $\beta$ approaches one the initial steady state moves closer and closer to the boundary. Figure 2 illustrates the factor space, the entropy boundary, and the inaccessible region of the factor space for this specification. We note that the production isoquants in this model are still asymptotic to the boundaries of the factor space, but because that boundary is not horizontal for oil, the isoquants become upward-sloping before they approach it. Because the upward-sloping regions of isoquants are not compatible with cost minimization, the economically feasible region of the factor space is smaller than that demarcated by the entropy boundary itself.

We will calibrate the short-run and long-run elasticities of substitution between $O_{t}^{J}$ and $M_{t}^{J}$ based on empirical evidence. For the Baseline Scenario the long-run elasticity is simply given by $\epsilon_{d}$, while the short-run elasticity can be considerably lower due to adjustment costs $\phi_{O}>0$. For the alternative specification the short-run elasticity is still below the long-run elasticity because of adjustment costs. But the formula for the long-run elasticity is now more complex, namely $\varepsilon_{d, t}^{J}=\epsilon_{d}^{J}\left(\frac{O_{t}^{J}}{M_{t}^{J}}-\beta \frac{\bar{O}^{J}}{M^{J}}\right) / \frac{O_{t}^{J}}{M_{t}^{J}}<\epsilon_{d}^{J}$. The critical feature of this elasticity is that it is time-varying. Specifically, with a tight entropy boundary (high $\beta$ ) the elasticity of substitution declines towards zero after an oil supply shock starts to drive the economy even closer to the boundary, while under the baseline specification the long-run elasticity remains constant at all times. We will calibrate the initial steady state of our model by adjusting each sector's $\epsilon_{d}^{J}$ such that the long-run elasticity equals $\bar{\varepsilon}_{d}^{J}=\epsilon_{d}$, where $\epsilon_{d}$ is the constant long-run elasticity from the Baseline Scenario. Finally, the economy-wide average elasticity of substitution across the three oil-using sectors will be one of our reporting variables for this scenario. It is given by the formula $\varepsilon_{d, t}=\left(\varepsilon_{d, t}^{N} O_{t}^{N}+\varepsilon_{d, t}^{T} O_{t}^{T}+\varepsilon_{d, t}^{C} O_{t}^{C}\right) /\left(O_{t}^{N}+O_{t}^{T}+O_{t}^{C}\right)$.

In essence the Entropy Boundary Scenario asserts that available quantities of oil could affect elasticities of substitution in the opposite direction in which the corresponding prices affect them under the Growing Elasticity Scenario. There is therefore also a reduced form specification that captures this notion in an equivalent form to (3). We refer to this as the Falling Elasticity Scenario. For this specification the price elasticity of oil demand is given by

$$
\log \left(\epsilon_{d, t}\right)=\log \left(\epsilon_{d}\right)+\epsilon_{\epsilon}^{o} \log \left(O_{t}^{a v g} / \bar{O}\right)
$$


where $O_{t}^{a v g}=\left(O_{t}\left(O_{t-1}^{a v g}\right)^{3}\right)^{\frac{1}{4}}$. We will present the results for this scenario alongside the Entropy Boundary Scenario. The reason for presenting both, as we will explain, is partly that we have encountered computational limits when solving the model under the Entropy Boundary Scenario.

\section{Technology Externality Scenario}

In this specification the production function takes the form

$$
Z_{t}^{J}=\left(\left(1-\eta^{J}\right)^{\frac{1}{\epsilon_{d}^{J}}}\left(M_{t}^{J}\right)^{\frac{\epsilon_{d}^{J}-1}{\epsilon_{d}^{J}}}+\left(\eta^{J}\right)^{\frac{1}{\epsilon_{d}^{J}}}\left(\left(\frac{\tilde{O}_{t}^{J}}{\bar{O}^{J}}\right)^{\xi^{J}} O_{t}^{J}\left(1-G_{O, t}^{J}\right)\right)^{\frac{\epsilon_{d}^{J}-1}{\epsilon_{d}^{J}}}\right)^{\frac{\epsilon_{d}^{J}}{\epsilon_{d}^{J}-1}}
$$

The term $\left(\tilde{O}_{t}^{J} / \bar{O}^{J}\right)^{\xi^{J}}$ represents oil-augmenting technology, with $\bar{O}^{J}$ denoting steady state oil use, and $\tilde{O}_{t}^{J}$ representing actual oil use. Agents treat $\tilde{O}_{t}^{J}$ as external when equating the value of the marginal product of oil to the price of oil, while in equilibrium we have $\tilde{O}_{t}^{J}=O_{t}^{J}$. This specification implies that the cost share of oil remains below its output contribution when $\xi^{J}>0$. The beneficial effects of oil are therefore not captured exclusively by the suppliers of oil, but rather by all factors of production, in the same way as for any other factor-augmenting technological change.

\section{World Oil Market Equilibrium}

Letting $i$ index the six regions of the world economy, the market clearing condition for the world oil market is given by

$$
\Sigma_{i=1}^{6} O_{t}^{\mathrm{sup}}(i)=\Sigma_{i=1}^{6}\left(O_{t}^{N}(i)+O_{t}^{T}(i)+O_{t}^{C}(i)\right),
$$

where the world oil price adjusts to equilibrate oil supply and oil demand.

\section{Calibration}

The long-term price elasticity of oil demand in both production and consumption is assumed to equal 0.08 , while the short-term elasticity, which reflects the interaction of the long-term elasticity and the size of adjustment costs, is around 0.02. This is consistent with estimates for 1990-2009 contained in Helbling and others (2011), and also with the Bayesian estimation results in Benes and others (2012).

In the baseline the contribution of oil to output is determined by the oil cost share. Based on a careful evaluation of recent historical data for the six regions of the model economy, this cost share has been calibrated at 2 to 5 percent, depending on the sector and region. 
The model assumes balanced growth, which means that the long-run income elasticity of oil demand is equal to one. This appears to be inconsistent with the data, as Helbling and others (2011) estimate a long-run income elasticity of only around one third at the world level (the short-term income elasticity is much higher, at 0.68), based on data from the period after 1990. This aspect will play a prominent role in our discussion of the results.

The literature contains far fewer studies that estimate the price elasticity of oil supply. But Benes and others (2012), who use a nonlinear Bayesian specification, are able to separately identify demand and supply elasticities. They find short-run price elasticities of supply, which represent the ability of oil producers to utilize existing spare capacity, of between 0.05 and 0.15 . They also separately estimate long-run price elasticities, which correspond almost exactly to the coefficient $\epsilon_{s}$ in our specification, and find them to be much lower at between 0.005 and 0.02 . Our specification omits short-run price elasticities, based on the reasonable assumption that the decline in the growth rate of world oil output in all our scenarios will eliminate spare capacity going forward. At the same time, our calibration of the long-run price elasticity of oil supply, at $\epsilon_{s}=0.03$, is slightly higher than the estimate of Benes and others (2012).

Because we model oil supply as an endowment, we need to specify how the revenue from oil sales is divided into extraction costs and payments to owners. We assume that, prior to the decline in the growth rate of oil supply, 40 percent of oil revenue must be used to pay for intermediate goods inputs, and that thereafter the real extraction cost per barrel of oil increases at a constant annual rate of 2 percent. The remainder of oil revenue is the oil rent, which is distributed between the private sector and the government. In the net oil-importing regions of our model economy, the government is assumed to receive only a very small portion of the oil rent. However, in oil exporters it is assumed to receive 90 percent, reflecting the fact that in many of these countries the oil sector is dominated by state-owned oil companies. Critically, we assume that governments do not immediately spend the additional funds, but that they accumulate them in a U.S. dollar-based fund that is spent gradually over time, at a rate of 3 percent per annum. One of the key effects of an increase in the oil price is therefore a dramatic increase in world savings due to the low propensity to consume out of oil revenues of oil exporters' governments.

\section{Discussion of the Alternative Specifications}

\section{A. Entropy Boundary and Falling Elasticity Scenarios}

Economists generally assume that elasticities of substitution between oil and other factors of production must be higher in the long run than in the short run. There are two possible reasons for this view. First, as in our Baseline Scenario, adjustment costs drive the short-run elasticity below the constant long-run elasticity $\epsilon_{d}$. Second, as in our Growing Elasticity Scenario, for persistently very high oil prices, $\epsilon_{d}$ may no longer be constant, but may instead grow with oil prices. On the other hand, several contributions in the natural sciences have objected that the assumption of a constant or growing long-run elasticity is not consistent with the historical facts (Smil (2010)), with real-world practical limits to substitution (Ayres (2007)), or with the laws of thermodynamics, specifically with entropy 
(Reynolds (2002)). In this paper we mathematically formalize Reynolds' entropy boundary as a Stone-Geary production function whereby the use of oil has to exceed a certain minimum multiple of the use of other factors of production. This implies that after an oil supply shock elasticities are very low in the short run (due to adjustment costs), significantly higher in the medium run (as adjustment costs are overcome), but potentially much lower again in the long run if the shock is sufficiently large, because there is a finite limit to the extent that machines (and labor) can substitute for oil. The Falling Elasticity Scenario attempts to capture the same logic in a reduced form.

The argument for an entropy boundary in the oil-capital/labor factor space requires a set of two interrelated arguments that draw on physics and engineering.

Entropy relates to energy rather than specifically to oil. It therefore affects the energy-capital/labor factor space. Entropy, or the Second Law of Thermodynamics, states that any ordered system naturally tends towards disorder through energy dissipation. Maintaining the system therefore requires the constant addition of a flow of energy. Applied to capital put in place to substitute away from energy, this means that such capital needs a continuing minimum input of energy to remain useful. A continuing input of capital, to offset depreciation, is not enough. Critically, this implies that only energy in excess of that minimum necessary amount can start to add to the output of goods. This puts a boundary on the factor space that can be accessed, with near-zero energy input not an option. When factor use comes close to that boundary, the elasticity of substitution between energy and other factors must go to zero.

To relate this concept to the oil-capital/labor factor space, we need to consider the relationship between oil and energy. If oil and other forms of energy had to be used in proportions that cannot change sufficiently, or sufficiently rapidly, an entropy boundary for energy implies an entropy boundary for oil. The two critical questions are therefore whether other energy sources can technically substitute for oil over realistic time horizons (years rather than decades) and at the required scale, and whether such energy sources have their own supply limitations. The argument that substitution away from oil would be extremely costly and time-consuming was first made by the Hirsch and others (2005) report for the U.S. Department of Energy, a government-supported analysis of the shortest time required to mitigate a decline in world oil production. This study claimed that the U.S. economy would require a lead time of at least 20 years to prepare alternatives to an oil-based economy, with any shorter preparation time implying serious transition problems. The 20-year estimate takes known saving and substitution possibilities into account. For the automotive sector this includes the possibility of using natural gas and electricity as alternatives to oil-based fuels, especially in densely populated areas.

We next discuss some of the energy alternatives to oil in more detail, both concerning their potential supply limitations, and concerning their technical substitutability for oil in specific applications.

\section{Supply Limitations}

We begin with the least plausible substitute for oil, renewables, and then move on to progressively closer substitutes. 
The renewables solar and wind are not even very substitutable for other forms of electricity generation on the scale required in the longer run. The problem is that both solar and wind are highly intermittent, while electricity grids collapse when supply cannot match demand to within around 0.5 percent. On current knowledge, solar and wind can therefore not supply more than $20 \%-30 \%$ of overall electricity without causing serious problems for grid stability. This percentage can be debated, and storage or smart grids can perhaps raise it, but at great cost, and not to the point where intermittency ceases to be an issue altogether. Furthermore, solar and wind cannot be produced and operated without oil-based components (solar panels, wind turbines), an oil-based transportation infrastructure, and most importantly a large and very costly backup capacity of fossil-fuel operated power plants to match demand when there is no wind or sun. This backstop problem is one of the reasons why the energy return on energy invested (EROEI) of renewables is very much lower than that of conventional oil. ${ }^{8}$

Biofuels such as ethanol also face significant supply limitations. While they are of course much more substitutable for oil than electricity, there are generally limits to how much biofuel can be blended into commercial fuel (5\% to $15 \%)$. But beyond that their problems include an extremely low EROEI, the fact that their production uses scarce water resources, and that it competes with food production, which is developing serious global bottlenecks of its own.

Given the shortcomings of renewables, one would therefore have to rely on one of the other major sources of energy, meaning coal, natural gas, or nuclear power, for a major part of either electricity generation or direct technical substitution.

Several authors have recently claimed that coal reserves have been greatly overstated in a number of countries ${ }^{9}$, and put the global peak of coal production about 20 years away. With several important individual countries reaching peak production much earlier than that, costly transportation of coal will also become a factor. The peak of coal production would of course come much faster if an attempted substitution towards coal was to be of a large scale. ${ }^{10}$

The peak of global gas production may be further away, especially with the hydraulic fracturing ("fracking") technology that has recently been much publicized. But at least in the United States a lot of the additional gas production from fracking has already been budgeted for the planned fuel switch from coal to natural gas in electricity generation. ${ }^{11}$ Another problem is that fracking is claimed in some quarters to have serious problems with environmental pollution, and has been stopped in a number of countries and jurisdictions for that reason. Finally, fracking is also very costly, because fracking wells

\footnotetext{
${ }^{8}$ EROEI is the ratio of the useful energy provided by a given energy source to the energy needed to produce it. There are significant measurement issues, because it is not trivial to compute useful energy, and because narrow or broad measures of energy used in production can be used. Hall and others (2009) claim that a society needs to operate with an overall EROEI of at least 3 to be sustainable, as otherwise a huge share of economic activity would need to be devoted exclusively to energy production. U.S. oil production currently exhibits an EROEI of around 20, while most renewables are below 3, with some approaching 1, where production obviously becomes completely pointless.

${ }^{9}$ See Heinberg (2009) for a comprehensive overview.

${ }^{10} \mathrm{Oil}$, coal and natural gas currently account for about 33, 28 and 23 percent, respectively, of primary energy consumption in the world (U.S. Energy Information Agency (2009)).

${ }^{11}$ The practice of double-counting new resources for a variety of substitutions is unfortunately rampant in parts of the literature.
} 
and fields exhibit extremely fast decline rates and therefore require constant new drilling to maintain production. Berman (2012) contains an excellent overview of the problems with natural gas for the U.S. case. They include an extreme acceleration of sector-wide average decline rates of gas wells, and therefore of extraction costs, and a large overstatement of field reserves for financial reporting reasons. If Berman's prognoses turn out to be correct, natural gas prices could soon begin a rapid rise that would significantly reduce its cost advantage over oil, and therefore the incentive to switch from oil to gas. The expectation that that cost advantage is not just large today but also highly persistent is critical, because a switch to electricity produced by natural gas would require the building of costly power plants, which have amortization periods of 30 years or more (Bishop and others (2012)), while a direct switch to natural gas as a transportation fuel, which is technically among the most realistic substitution possibilities, would require the installation of a costly network of filling stations. ${ }^{12}$

As for nuclear power, Dittmar (2011) recently estimated that if large-scale substitution from fossil fuels towards nuclear power was attempted, the benefits would be very short-lived because the world would hit a peak in uranium production in short order. But this finding is highly controversial, with others claiming that different reactor types would eliminate problems with fuel supply for the foreseeable future. In any event, the worldwide trend seems to be going away from rather than towards nuclear power, due to the fear of low-probability but extremely high-cost events such as Fukushima.

To summarize, other non-renewable energy sources may also have supply limits, and there is at least a possibility that they may not be able to provide energy security over the long run.

\section{Technical Substitutability}

In addition to supply limits there are also limits to the technical substitutability of coal, gas or electricity for oil. We start with the observation that the main uses of oil in today's economy are as a liquid transportation fuel and as a feedstock for the chemical industry. Critical considerations for technical substitutability include, relative to any specific application, storability, transportability, and most importantly the ability to deliver useful energy. An example is the impossibility of running an airplane with coal, which is due to coal's physical properties rather than simply its energy content.

The most important use of oil today is in transportation. The properties of oil, or more generally liquid fuels, in this application are far superior to the alternatives. In some cases a transition towards a transportation infrastructure based on electricity, natural gas and/or liquid fuels derived from non-oil sources may be possible by retrofitting existing equipment or building differently configured new equipment. But a large-scale transition would be enormously expensive in terms of dollars ${ }^{13}$, in terms of energy, and most importantly in terms of time - the transition would require several decades. This, according to the best available scientific evidence (Hirsch and others (2005), UK Energy Research Centre (2009)), is time that we may not have.

\footnotetext{
${ }^{12}$ Gas filling stations require significantly greater safety precautions than conventional filling stations.

${ }^{13}$ This is why coal-to-liquids or gas-to-liquids industries have not yet been established on a significant scale, except in countries that have faced economic sanctions or economic isolation.
} 
The second main use of oil today is as a feedstock of the chemical industry. Oil products are in virtually every single product we consume, either directly, or in the mining of the respective raw materials, in transportation or in processing. In most cases there simply is no easy substitute for oil derivatives in these applications, although in some specific cases there are possibilities to derive the chemicals from coal or gas instead.

\section{B. Growing Elasticity Scenario}

For the next several years substitution away from oil and towards gas or electricity may be sufficient to delay the moment at which lower oil availability could cause serious economic problems. Given the proven technical feasibility of some substitution technologies, such as gas-powered vehicles, and to a lesser extent coal-to-liquids and gas-to-liquids, it may therefore be reasonable to assume that price elasticities of demand have scope to rise for a number of years. This is true even if one were to subscribe to the view that the alternatives have significant supply limitations in the not too distant future, that they can only technically substitute for oil in a limited number of applications, and that attempts to economize on oil use may soon run into limits dictated by entropy. It is for this reason that we include the Growing Elasticity Scenario in this study. It is impossible to know at the present time which effect on price elasticities of oil demand will be stronger and for how long.

\section{Technology Externality Scenario}

For the contribution of oil to GDP, the main problem is that conventional production functions imply an equality of cost shares and output contributions of oil. This has led economists to conclude that, given its historically low cost share of around $3.5 \%$ for the U.S. economy ${ }^{14}$, oil can never account for a massive output contraction, even with low elasticities of substitution between oil and other factors of production. There are two counterarguments to this. First, if oil prices were to permanently rise sharply due to supply shocks, then cost shares would become high enough to worry even if output contributions equalled cost shares. Second, several recent articles and books by natural scientists have argued that output contributions of energy/oil need not equal cost shares with a more appropriate modeling of the aggregate technology. The contributions include Ayres and Warr (2005, 2010), Hall and Klitgaard (2011), Kümmel (2011), and Kümmel and others (2002), who propose alternative production functions that are based on concepts from engineering and thermodynamics. In our alternative specification oil enters externally in a similar fashion to technology. This feature can yield output contributions of oil that are higher than cost shares as long as $\xi^{J}>0$.

\footnotetext{
${ }^{14}$ See http://www.eia.gov/oiaf/economy/energy_price.html.
} 


\section{Simulation Results}

Figures 3-8 present the results of our simulations. Variables are shown, where applicable, relative to trend. The first column shows the evolution of the world oil supply, the real oil price (in terms of U.S. goods), and the world average real interest rate. The second column shows real GDP, real absorption, and the current account-to-GDP ratio for oil exporters. ${ }^{15}$ The third and fourth columns show the same three variables for the United States plus Euro Area region, and for the Rest of the World group of countries. Aggregations across regions of the world economy use purchasing power parity (PPP) weights to fix relative country sizes. As shown in Helbling and others (2011), there are some interesting further differences in the reactions of individual regions to higher oil prices, but the common features across regions are far more interesting, and we have therefore decided to focus on them in this paper. The year in which the oil supply shock hits the economy is denoted by $\tau$, and as mentioned above a range of different values for $\tau$ are justifiable.

\section{A. Baseline Scenario}

The Baseline Scenario analyzes the impact of a decline in the average growth rate of world oil production by 1 percentage point below its historical trend growth rate starting in year $\tau$, with an eventual return to the initial growth rate in year $\tau+30 .{ }^{16}$ As in all simulations that follow, agents are assumed to be surprised by the shock, but thereafter they perfectly foresee the future evolution of world oil production.

The shock generates an immediate oil price spike of over 60 percent. This reflects the very low short-term price elasticity of oil demand. Because the decline in supply is persistent, the real oil price continues to increase thereafter, as market equilibrium requires ongoing demand destruction. Over 10- and 20-year horizons, the cumulative oil price increases amount to just over 100 percent and 200 percent. The 10-year result is extremely close to the point forecast in Benes and others (2012).

The reduced availability of oil, and the resulting higher oil prices, lead to a reduction in GDP levels, and to larger current account deficits, in oil importers. In the short term the global adjustment is also shaped by the wealth transfer from oil importers to oil exporters, which has effects on trade and capital flows.

With rising oil prices, oil exporters experience sustained increases in income and wealth. As a result, their domestic demand (domestic absorption) increases ahead of GDP, at an initial rate of over 2 percent annually. Higher spending leads to upward domestic price pressures and a large real appreciation. This "Dutch disease" effect reduces output in the tradables sector (other than oil), thereby reducing GDP by up to 7 percent below trend over the first five years, and by almost 10 percent after 20 years. The current account improvement in this group of countries, which equals up to 4 percent of GDP in the very short run and almost 8 percent after 20 years, is due entirely to the higher value of oil

\footnotetext{
${ }^{15}$ Oil exporters include the following countries: Algeria, Angola, Azerbaijan, Bahrain, Canada, Republic of Congo, Equatorial Guinea, Iraq, Kuwait, Libya, Mexico, Nigeria, Norway, Oman, Qatar, Russia, Saudi Arabia, United Arab Emirates and Venezuela.

${ }^{16}$ For technical reasons it is not possible to simulate a completely permanent shock to this growth rate.
} 
exports, with the initial spike in oil prices explaining the large current account surplus at that time. Goods exports fall substantially relative to GDP, and the non-oil current account deteriorates. But the government's very low propensity to consume out of the oil fund limits the size of that deterioration.

Oil importers' absorption contracts over time as a result of the negative wealth effect of higher oil prices, at an average rate of around 0.5 percent per annum. Their GDP also declines, but only moderately, by 0.2 to 0.4 percent per annum. ${ }^{17}$ World real interest rates gradually drop, and after 20 years are 60 basis points below their initial value. The reason is that oil exporters' additional oil revenue, which accrues primarily to governments, leads to higher saving. This effect is reminiscent of the international lending boom in the 1970s and early 1980s following large oil price increases.

These dynamics will look somewhat unfamiliar to those accustomed to studying historical oil price shocks. For GDP, as Hamilton (2009) shows, such episodes were typically characterized by a sizable but transitory contraction in oil output accompanied by a spike in oil prices, with GDP declining temporarily but sharply. Under such circumstances, real oil prices quickly return to earlier levels after the unwinding of the recession. The key feature accounting for the different predictions under our scenario is that the shock to oil production and therefore the loss in output is assumed to be much smaller initially, but also far more persistent than anything observed to date. For interest rates, the earlier episodes were characterized by high inflation, not exclusively caused by higher oil prices, which led to a tightening in monetary policy. In our simulation inflation remains subdued, partly because the oil price shock is moderate but persistent rather than large and transitory, but mainly because monetary policy is assumed to start from a situation where inflationary expectations are under control.

Global imbalances worsen in this scenario over the short to medium term. The United States and euro area current accounts deteriorate immediately as a result of costlier oil imports, while during a lengthy transition period the current accounts of the other regions remain stronger, as they export more goods to oil exporters. But they eventually also deteriorate. The long-run effects are not particularly large, however, with oil importers' current account-to-GDP ratios on average deteriorating by at most a little over 1 percentage point by year $\tau+20$. This is explained by the relatively low aggregate cost share of oil.

In the following subsections we explore the sensitivity of our results to a number of assumptions. In most cases the Baseline Scenario results are shown as a solid blue line, and then compared to alternative scenarios.

\section{B. Growing Elasticity Scenario}

Figure 4 illustrates how the results change if the price elasticity of demand for oil $\epsilon_{d, t}$ is elastic with respect to the oil price as per equation (3), with the red line showing the case of $\epsilon_{\epsilon}^{p}=1$ and the green line the case of $\epsilon_{\epsilon}^{p}=2$. Our comments focus on the case $\epsilon_{\epsilon}^{p}=2$,

\footnotetext{
${ }^{17}$ Regional differences in the size of the long-term output effects reflect differences in the shares of oil in production and consumption.
} 
where we observe that the oil price only needs to rise by half as much as in the Baseline Scenario to bring about the necessary substitution. The effects on GDP are positive everywhere, with roughly 50 percent smaller contractions in oil exporters, the United States and the euro area, and an even larger turnaround in the Rest of the World countries, where an 8 percent output loss over 20 years turns into a 2 to 3 percent output gain.

The latter is driven mainly by emerging Asia and to a lesser extent Japan. Under the Baseline Scenario these two regions, whose production is heavily manufacturing-based and therefore oil-intensive, suffer very large contractionary effects of lower oil availability and higher oil prices. Under the Growing Elasticity Scenario, where oil is less critical because of its higher substitutability, these contractionary effects are much smaller, and two countervailing effects are now strong enough to raise rather than contract output. The first of these is a surge in goods exports to oil importers to satisfy their increasing domestic demand. Emerging Asia and Japan have particularly strong export linkages to oil exporters and therefore benefit disproportionately. The second countervailing effect is a surge in investment demand in response to lower world real interest rates, which is particularly strong in emerging Asia because of its higher steady state investment-to-GDP ratio.

As for global current account imbalances, these are less severe under this scenario, with smaller surpluses for oil exporters and emerging Asia, and smaller deficits for the larger oil importers.

\section{Entropy Boundary Scenario and Falling Elasticity Scenario}

Figure 5 illustrates four simulations of our Baseline Scenario shock, with the technology now given by (4), and for the cases of $\beta \in\{0,0.3,0.6,0.9\}$. The case of $\beta=0$ is identical to the Baseline Scenario. For larger $\beta$ the entropy boundary is tighter, in other words closer to initial steady state factor allocation, which means that further substitution away from oil becomes harder at a faster rate. The bottom left panel of Figure 5 shows the average elasticity of substitution $\varepsilon_{d, t}$.

We observe that for a tighter entropy boundary the increase in the oil price is significantly larger. The reason is that the elasticity of substitution moves closer to zero as the supply constraint starts to get progressively worse. For the tightest boundary $(\beta=0.9)$ the oil price increases by almost 300 percent rather than by 200 percent after 20 years.

Oil exporters experience a larger positive wealth effect if $\beta$ is larger. The resulting larger absorption, real exchange rate appreciation and "Dutch disease" effect cause a larger initial output contraction in that region, but eventually output in that region also experiences a larger rebound, because over time governments start to spend more and more of the accumulated oil surpluses, which are now larger due to higher oil prices. Oil importers experience worse contractions in absorption and output when the economy starts closer to the entropy boundary, and current account imbalances get larger, but the size of these effects is fairly small.

The reason is partly computational. For all simulations reported in this paper except for 
the Entropy Boundary Scenario we were able to simulate the full nonlinear model. This is important for the quantitative results because the real effects of higher oil prices increase nonlinearly as oil prices rise to very high levels. For the Entropy Boundary Scenario however we had to rely on numerical linearization ${ }^{18}$, which means that the real effects of the oil shock are understated.

Figure 6, which reports the Falling Elasticity Scenario, does not suffer from the same problem. As mentioned above, this scenario captures the same basic idea as the Entropy Boundary Scenario in a reduced form that directly relates the price elasticity of oil demand to the quantity of available oil as per equation (5). In this case we note that the worst scenario shown in Figure 6 generates a very similar decline in the overall elasticity of substitution to the worst scenario in Figure 5. But while the increase in the oil price is significantly smaller, at around 250 percent, the output effects are significantly worse, especially in the rest of the world where the reduction in the annual GDP growth rate rises from 0.4 percent to 0.6 percent.

\section{Technology Externality Scenario}

Figure 7 compares the Baseline Scenario to three further alternatives. The first of these assumes that the output contribution of oil is larger than its cost share because $\xi^{J}>0$ in equation (6). Specifically, it assumes that the contribution of oil to output, either directly or as technology, amounts to 25 percent in the tradables sector and 20 percent in the nontradables sector, rather than 5 percent and 2 percent, as in the baseline. ${ }^{19}$ The simulation, shown as the red line in Figure 7, shows that oil prices now increase by almost 400 percent after 20 years, rather than 200 percent as in the baseline. There are sizeable effects on growth, with the deterioration in all oil-importing regions' GDP larger by around a factor of three than in the baseline. Part of the reason for the size of this effect is that with our specification both oil and the technologies dependent on oil have a very low elasticity of substitution with other factors of production, so that a sizeable contraction in oil output cannot easily be compensated for by replacing oil with other factors, and oil-based technologies with other technologies. A higher output contribution of oil also has significant effects on oil importers' current accounts, which in the longer run deteriorate by almost twice as much as in the baseline. Savings imbalances cause world real interest rates to drop by approximately twice as much as in the baseline, or around 1.2 percentage points after 20 years.

\section{E. Larger Shock Scenario}

Sorrell and others (2010) discuss several studies which conclude that world oil production is currently on a temporary and fluctuating plateau, and which forecast future decline

\footnotetext{
${ }^{18}$ In numerical linearization we first divide the size of the shock by a certain factor, then we perform the nonlinear model simulation for this smaller shock, and finally we multiply the simulation result by the same factor.

${ }^{19}$ Of course this effect is only present in the manufacturing sector where oil is used as an intermediate input, and not in the consumption sector where oil is part of the consumption bundle. Note that this is different from the entropy boundary, which is present in all three sectors.
} 
rates of around 2 percent per annum. The second alternative scenario in Figure 7, shown as the yellow line, therefore considers the implications of a 3.8 percent rather than 1 percent annual decline in world oil output growth. Given an initial growth rate of 1.8 percent per annum in the data, this implies that, except for the small supply response to higher oil prices, oil production declines by 2 percent annually. We also assume that this outright output contraction is accompanied by an annual increase in real extraction costs per barrel of 4 percent rather than 2 percent.

In this scenario, the longer-term output and current account effects are approximately four times as large as in the baseline, in other words they increase roughly in proportion to the size of the shock. Declines in absorption in oil importers now average around 2 percent annually over the period shown, rather than 0.5 percent as in the baseline. Annual GDP growth rates in the United States and the euro area drop by around one percentage point, rather than 0.25 percentage points as in the baseline. Current account deteriorations in oil importers are also much more serious, averaging 5 percentage points of GDP on average in the long term in both the United States and the euro area.

The most striking aspect of this scenario is however that supply reductions of this magnitude would require a more than 200 percent increase of the oil price on impact, and an 800 percent increase over 20 years. Relative price changes of this magnitude would be unprecedented, and would almost certainly have nonlinear effects on GDP that the model is not able to capture adequately. Furthermore, the increase in world savings implied by this scenario is so large that several regions could, after the first few years, experience nominal interest rates that approach zero, which could create difficulties for the conduct of monetary policy.

\section{F. Combined Downside Scenarios}

So far we have analyzed each potential aggravating factor in isolation. If they were to occur in combination, the effects could become even more severe. In this paper we only discuss one such combination, namely the Technology Externality Scenario combined with the Larger Shock Scenario. This is illustrated by the yellow line in Figure 7.

Technically the model can still be simulated for this case, but the effects now become so large that some aspects are no longer plausible. Most importantly, real oil prices under this scenario would increase by over 400 percent on impact, and by around 1400 percent after 20 years. Despite this, there is no sharp crisis in the short run, and the subsequent reduction in annual GDP growth rates in oil importers equals a steady, crisis-free 3 percentage points.

Real-world response mechanisms to such extreme increases in oil prices could in principle take one of two possible forms. One is a much more urgent search for alternatives to oil, reflected in much higher elasticities of substitution. We study this in the following subsection. The other is a much sharper contraction in aggregate demand. The model in its current form is unable to deliver this. If output were to contract far more sharply at the simulated oil prices, the resulting demand destruction would in turn limit the required increase in oil prices. We return to this question in Section IV.I. 


\section{G. Combined Downside and Growing Elasticity Scenario}

In Figure 8 we combine the worst case of Figure 7 with the Growing Elasticity Scenario. For the case of $\epsilon_{\epsilon}^{p}=2$ we observe that the increase in the oil price is only half as large, and so are, approximately, the output effects. But this still leaves an oil price increase of 800 percent after 20 years. More broadly, unless the increase in the price elasticity of demand in response to higher oil price is extreme, and we have discussed above why this is not likely, then the worst of our downside scenarios would still force the economy to cope with entirely unprecedented increases in oil prices. In the real world, if such a scenario came to pass, the more likely outcome would therefore include not only higher elasticities of substitution but also a larger output contraction.

\section{H. The Assumption of Unitary Income Elasticity}

As discussed in Section II.D, our model assumes a unitary income elasticity of oil demand, while the data suggest a much lower income elasticity of around one third. This empirical regularity probably reflects the fact that much recent growth worldwide has been due to the services sector, which uses less oil per unit of output. While a low income elasticity may appear like a blessing in an environment where oil output can grow without constraints, it actually makes the problem of supply constraints all the more severe. The reasoning is simple-minded, but nevertheless approximately true because very low price elasticities limit the extent of substitution away from oil. Namely, if it really only takes a one third of one percentage point increase in oil supply per annum to support additional GDP growth of one percentage point, then it must also be true that it would only take a one third of one percentage point decrease in oil supply growth to reduce GDP growth by a full percentage point. And the kinds of declines in oil supply growth that are now being discussed as realistic possibilities are far larger than one third of one percentage point.

\section{The Assumption of Smooth Reallocation}

In each of the scenarios in Sections IV.B to IV.G, the transition to a new equilibrium is smooth by assumption. Consumers in oil exporters easily absorb large surpluses in goods exports from oil importers, financial markets efficiently absorb and intermediate a flood of savings from oil exporters, businesses respond flexibly to higher oil prices by reallocating resources, and workers readily accept lower real wages. Some of these assumptions may be too optimistic.

Historical experience suggests caution when it comes to the efficient intermediation of large net capital flows from oil exporters' governments. If not efficiently allocated, risk premia could increase in parts of the world where borrowers are vulnerable. This, in turn, could prevent borrowers from taking advantage of lower risk-free interest rates, which is an important mitigation mechanism in the face of oil scarcity. If private as well as public saving rates were to increase in oil-exporting countries, this problem could intensify.

A smooth reallocation of resources among inputs and across sectors as the economy adjusts to less oil is also a very strong assumption. Unlike in the model, real economies have many 
and highly interdependent industries, and several industries, including car manufacturing, airlines, trucking, long-distance trade, and tourism, would be affected by an oil shock much earlier and much more seriously than others. The adverse effects of large-scale bankruptcies in such industries could spread to the rest of the economy, either through corporate balance sheets (intercompany credit, interdependence of industries such as construction and tourism) or through bank balance sheets (lack of credit after loan losses).

In recent years, labor market flexibility has helped to improve the absorption of oil shocks (Blanchard and Galí (2007)). In the case of larger and more persistent oil price increases, however, workers may resist a series of real wage cuts. This, while perhaps mitigating the distributional consequences of the oil shock, could significantly raise the output cost of the shock during the long transition period.

Finally, the simulations do not consider the possibility that some oil exporters might withhold an increasing share of their stagnating or decreasing oil output for domestic use, for example through fuel subsidies, in order to support energy intensive industries (e.g. petrochemicals), and also to forestall domestic unrest. If this were to happen, the amount of oil available to oil importers could shrink much faster than world oil output (Brown and Foucher (2010)), with obvious negative consequences for growth in those regions.

\section{Conclusion}

The scenarios developed in this paper highlight that the extent to which persistent oil scarcity could constrain global economic growth and current account imbalances depends critically on a small number of key factors. If, as in our baseline, the trend growth rate of oil output declined only modestly, and if the economy was adequately represented by a standard production function in capital, labor and oil, world output would eventually suffer, but the effect might not be dramatic. If the substitutability between oil and other factors of production was increasing in the oil price, the effect would be even smaller. But if the reductions in oil output were more in line with the more pessimistic studies in the scientific literature, the effects could be extremely large. The same could be true if, as claimed by several authors in the scientific literature, standard production functions miss important aspects of the economic role of oil under conditions of scarcity. We discussed three possibilities. First, if the economy attempted to substitute away from oil, it might encounter a lower limit of oil use dictated by entropy. Second, the contribution of oil to output could be much larger than its cost share, because oil is an essential precondition for the continued viability of many modern technologies. Third, the income elasticity of oil demand could be equal to one third as in some empirical studies, rather than one as in our model. And if two or more of these aggravating factors were to occur in combination, the effects could range from dramatic to downright implausible. 


\section{References}

Ayres, R. (2007), "On the Practical Limits to Substitution", Ecological Economics, 61, 115-128.

Ayres, R. and Warr, B. (2005), "Accounting for Growth: The Role of Physical Work", Structural Change and Economic Dynamics, 16, 181-209.

Ayres, R. and Warr, B. (2010), The Economic Growth Engine - How Energy and Work Drive Material Prosperity, Edward Elgar Publishing.

Benes, J., Chauvet, M., Kamenik, O., Kumhof, M., Laxton, D., Mursula, S. and Selody, J. (2012), "The Future of Oil: Geology versus Technology", IMF Working Paper $\mathrm{WP} / 12 / 109$.

Berman, A. (2012), "After The Gold Rush: A Perspective on Future U.S. Natural Gas Supply and Price", Energy Bulletin, February.

Bishop, R., Baggot, R., Kelley, W. and Fargo, R. (2012), "US Shale Oil - Shale Gas Production Potential, Part 2", Oil \& Gas Journal (forthcoming).

Blanchard, O. and Galí, J. (2007), "The Macroeconomic Effects of Oil Shocks: Why Are the 2000s So Different from the 1970s?", NBER Working Paper No. 13368.

Brown, J. and Foucher, J. (2010), "Peak Oil versus Peak Exports", Energy Bulletin, available at http://www.energybulletin.net/stories/2010-10-18/peak-oil-versus-peak-exports.

Deffeyes, K. (2005), Beyond Oil: The View from Hubbert's Peak, Hill and Wang.

Dittmar, M. (2011), "The End of Cheap Uranium", Working Paper, Institute of Particle Physics, ETH, Switzerland.

Hall, C, Balogh, S. and Murphy, D. (2009), "What is the Minimum EROI that a Sustainble Society Must Have?", Energies, 2, 25-47.

Hall, C. and Klitgaard, K. (2011), Energy and the Wealth of Nations: Understanding the Biophysical Economy, Springer Verlag (forthcoming, June 2011).

Hamilton, J. (2009), "Causes and Consequences of the Oil Shock of 2007-08", Brookings Papers on Economic Activity, 215-261.

Heinberg, R. (2009), Blackout - Coal, Climate and the Last Energy Crisis, New Society Publishers.

Helbling, T., Kang, J.S., Kumhof, M., Muir, D., Pescatori, A. and Roache, S. (2011), "Oil Scarcity, Growth, and Global Imbalances", World Economic Outlook, April 2011, Chapter 3, International Monetary Fund.

Hirsch, R., Bezdek, R. and Wendling, R. (2005), "Peaking of World Oil Production: 
Impacts, Mitigation and Risk Management", United States Department of Energy.

Hirsch, R., Bezdek, R. and Wendling, R. (2010), The Impending World Energy Mess, Apogee Prime.

Hubbert, M.K. (1956), "Nuclear Energy and the Fossil Fuels", American Petroleum Institute Drilling and Production Practice Proceedings, pp. 5-75.

Kumhof, M., Laxton, D., Muir, D. and Mursula, S. (2010), "The Global Integrated Monetary and Fiscal Model - Theoretical Structure", IMF Working Paper $\mathrm{WP} / 10 / 34$.

Kümmel, R. (2011), The Second Law of Economics - Energy, Entropy, and the Origins of Wealth, Springer Verlag.

Kümmel, R., Henn, J. and Lindenberger, D. (2002), "Capital, Labor, Energy and Creativity: Modeling Innovation Diffusion", Structural Change and Economic Dynamics, 13, 415-433.

Reynolds, D. (2002), Scarcity and Growth Considering Oil and Energy: An Alternative Neo-Classical View, Edwin Mellen Press.

Smil, V. (2010), Energy Transitions - History, Requirements, Prospects, Praeger.

Sorrell, S., Miller, R., Bentley, R. and Speirs, J. (2010), "Oil Futures: A Comparison of Global Supply Forecasts", Energy Policy, 38, 4990-5003.

UK Energy Research Centre (2009), "Global Oil Depletion - An Assessment of the Evidence for a Near-Term Peak in Global Oil Production".

United States Energy Information Administration (2009), International Energy Outlook, Washington, DC.

United States Government Accountability Office (2007), "Crude Oil: Uncertainty about Future Oil Supply Makes It Important to Develop a Strategy for Addressing a Peak and Decline in World Oil Production", Report to Congressional Requesters.

United States Joint Forces Command (2010), "The Joint Operating Environment 2010". 
Figure 1. World Crude Oil Production (in million barrels per day)

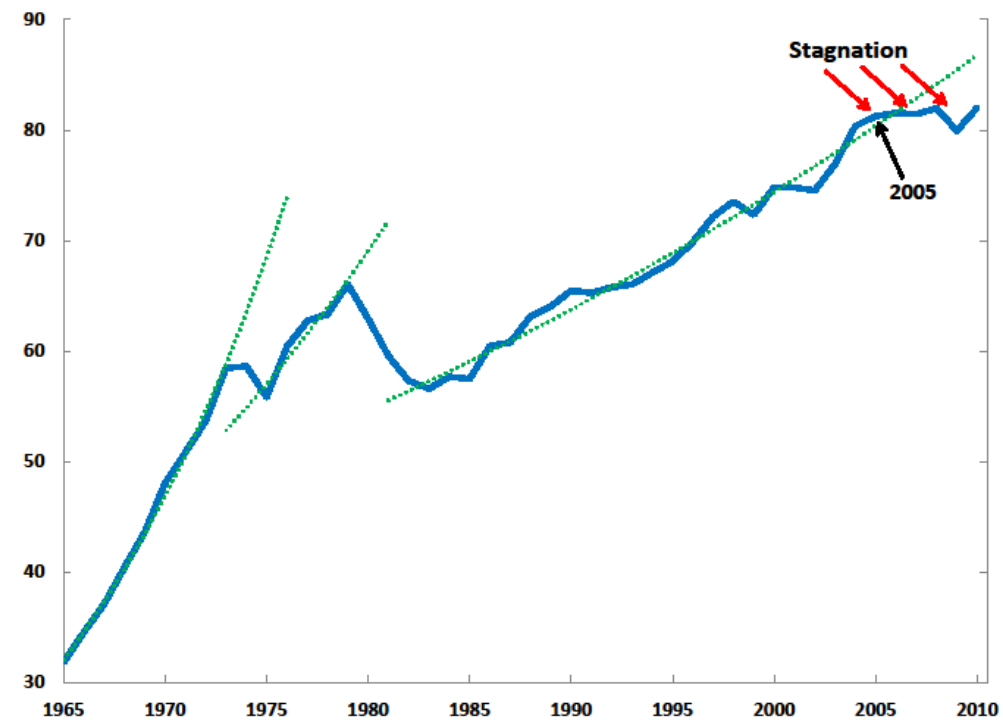

Figure 2. The Entropy Boundary in Factor Space

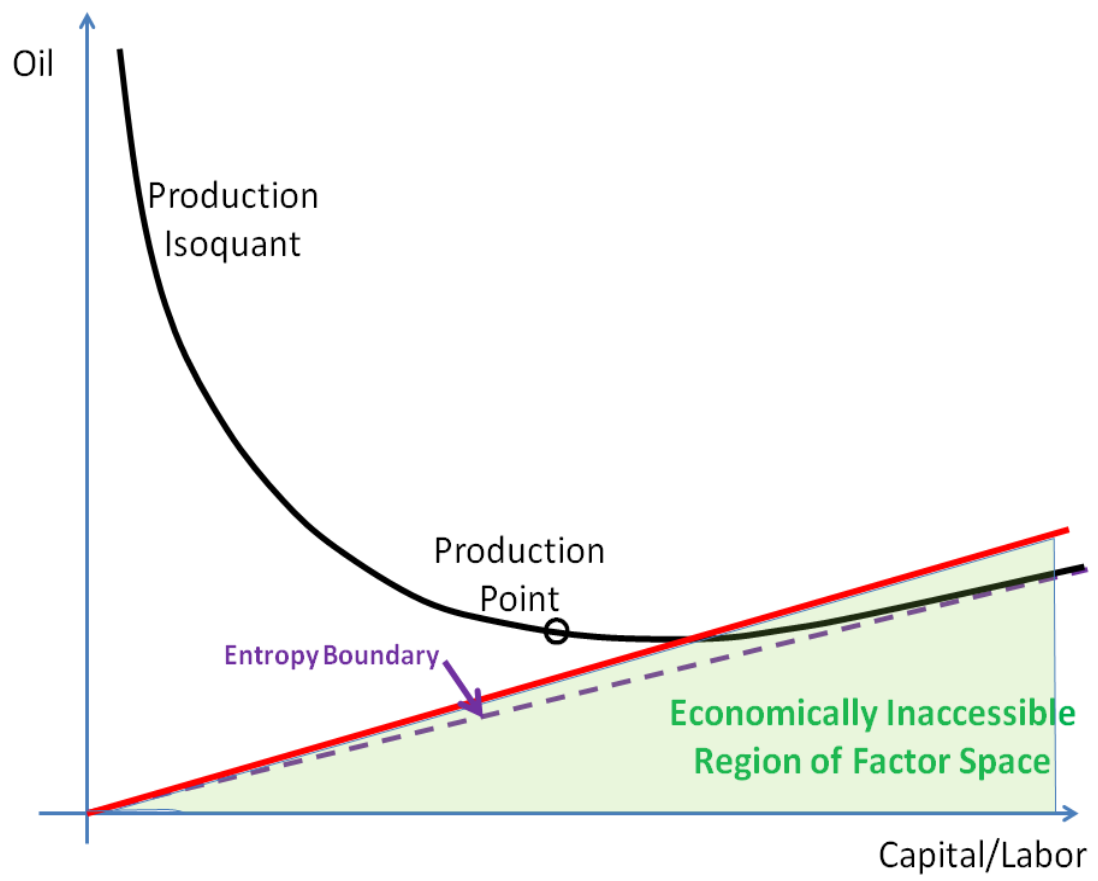


Figure 3. Baseline Scenario
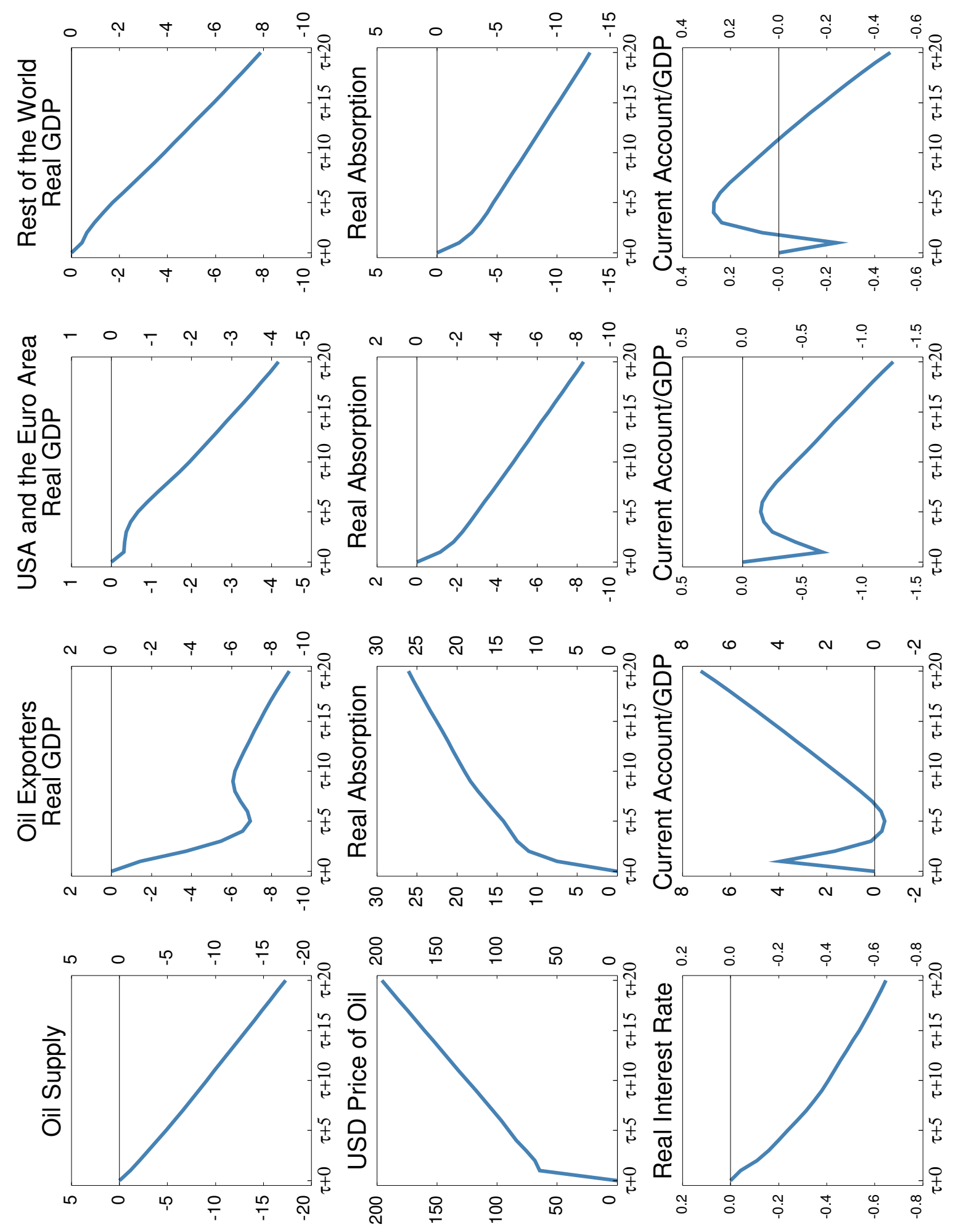
Figure 4. Growing Elasticity Scenario
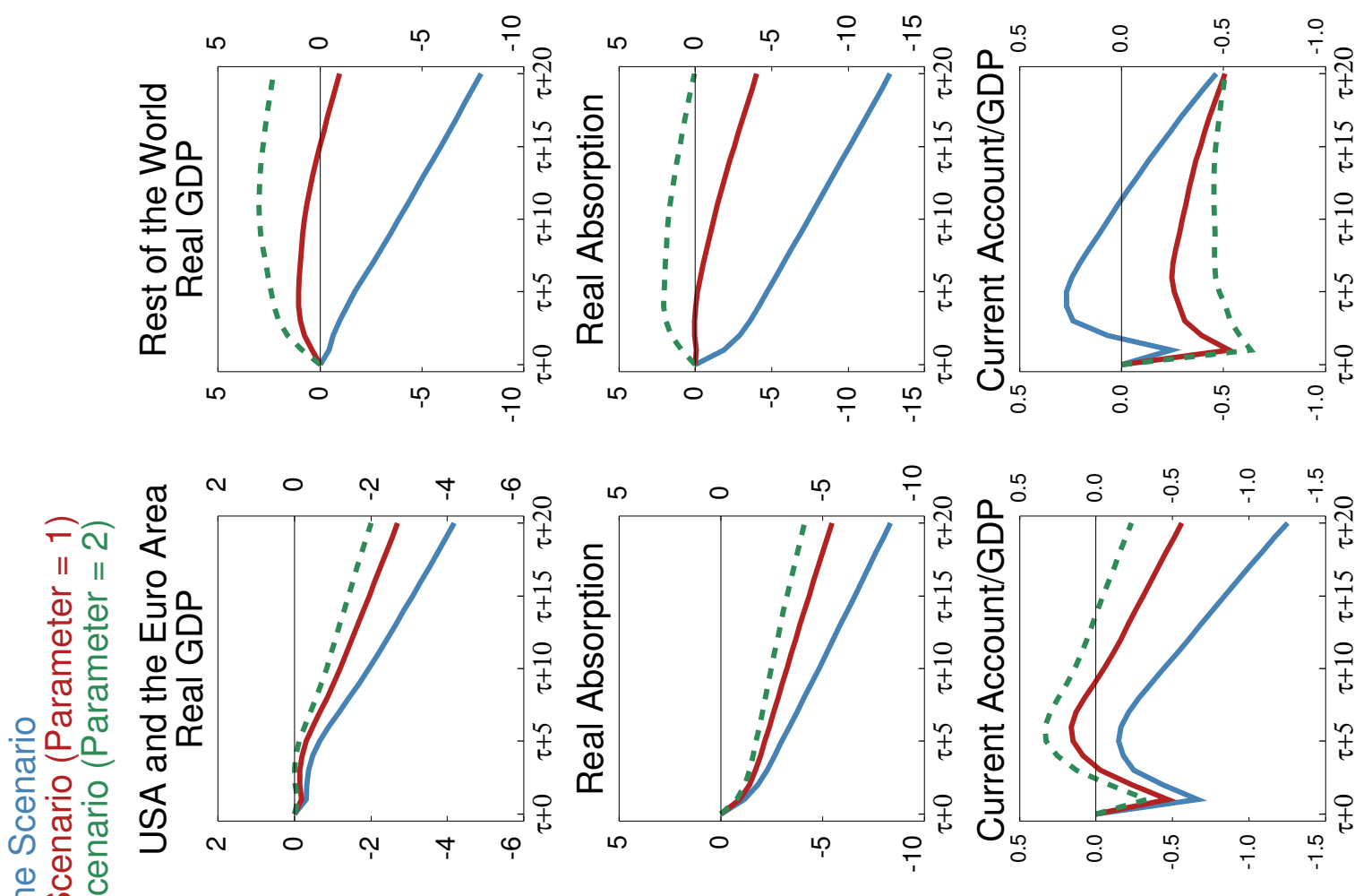

(1) ভ
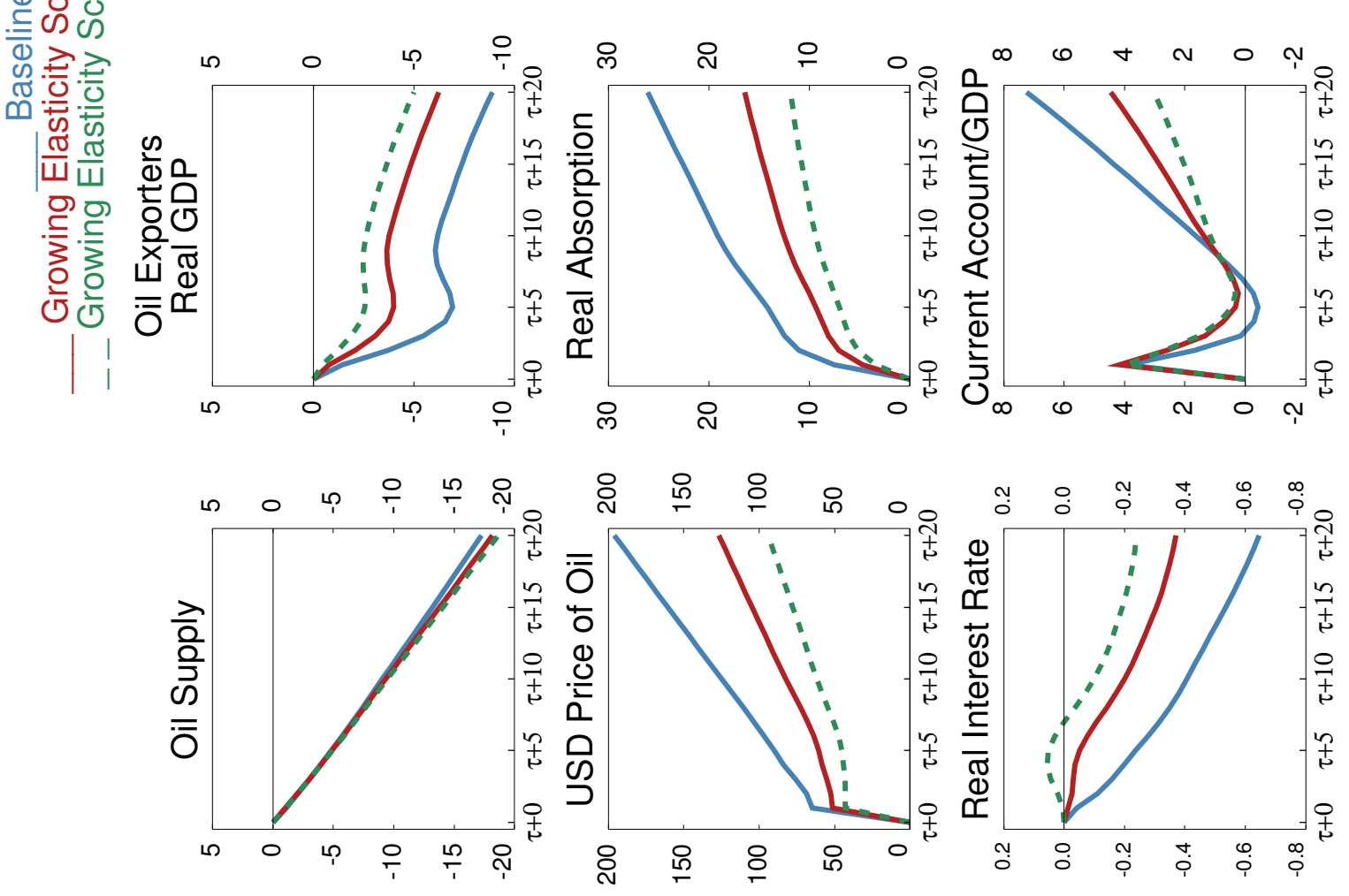
Figure 5. Entropy Boundary Scenario
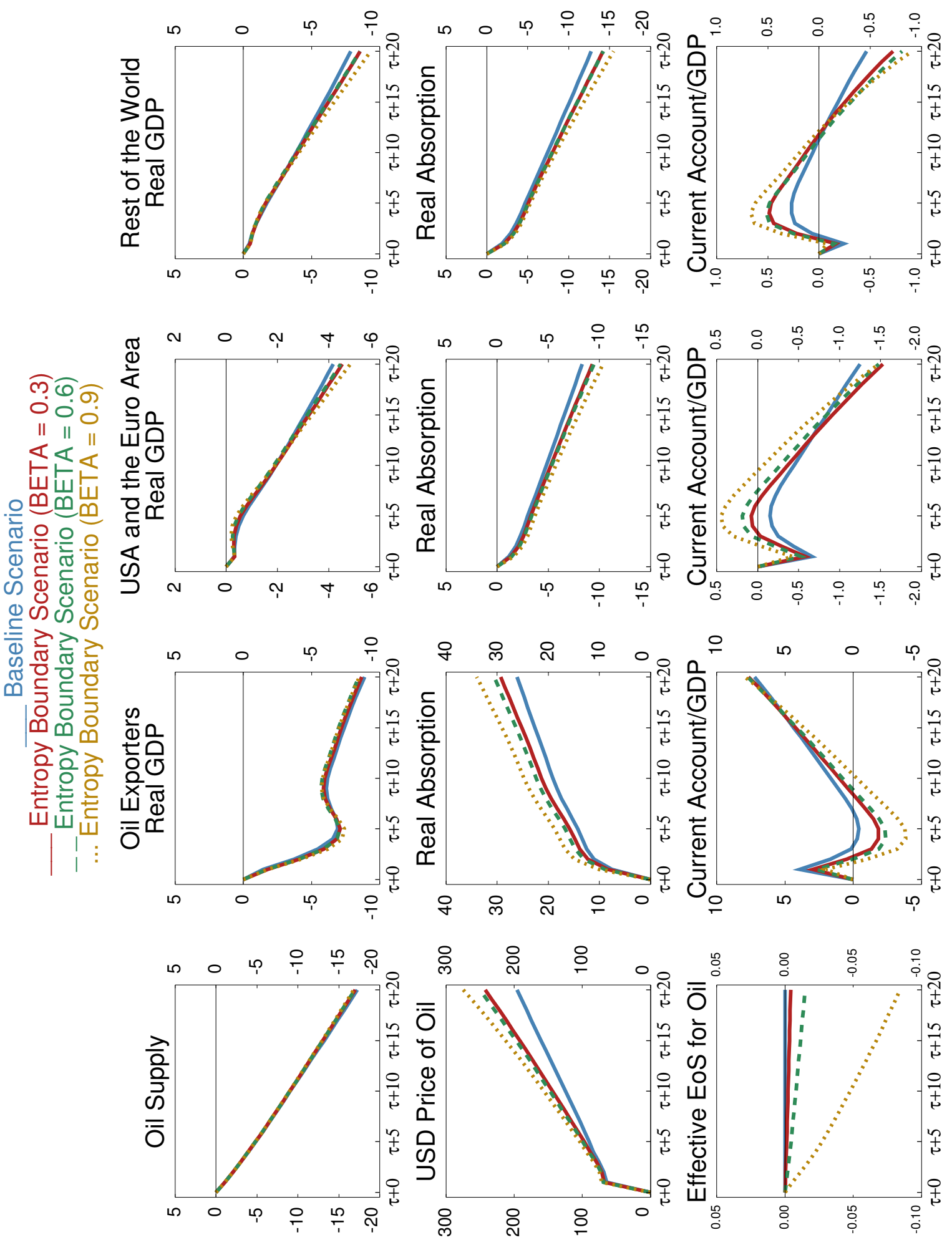
Figure 6. Falling Elasticity Scenario
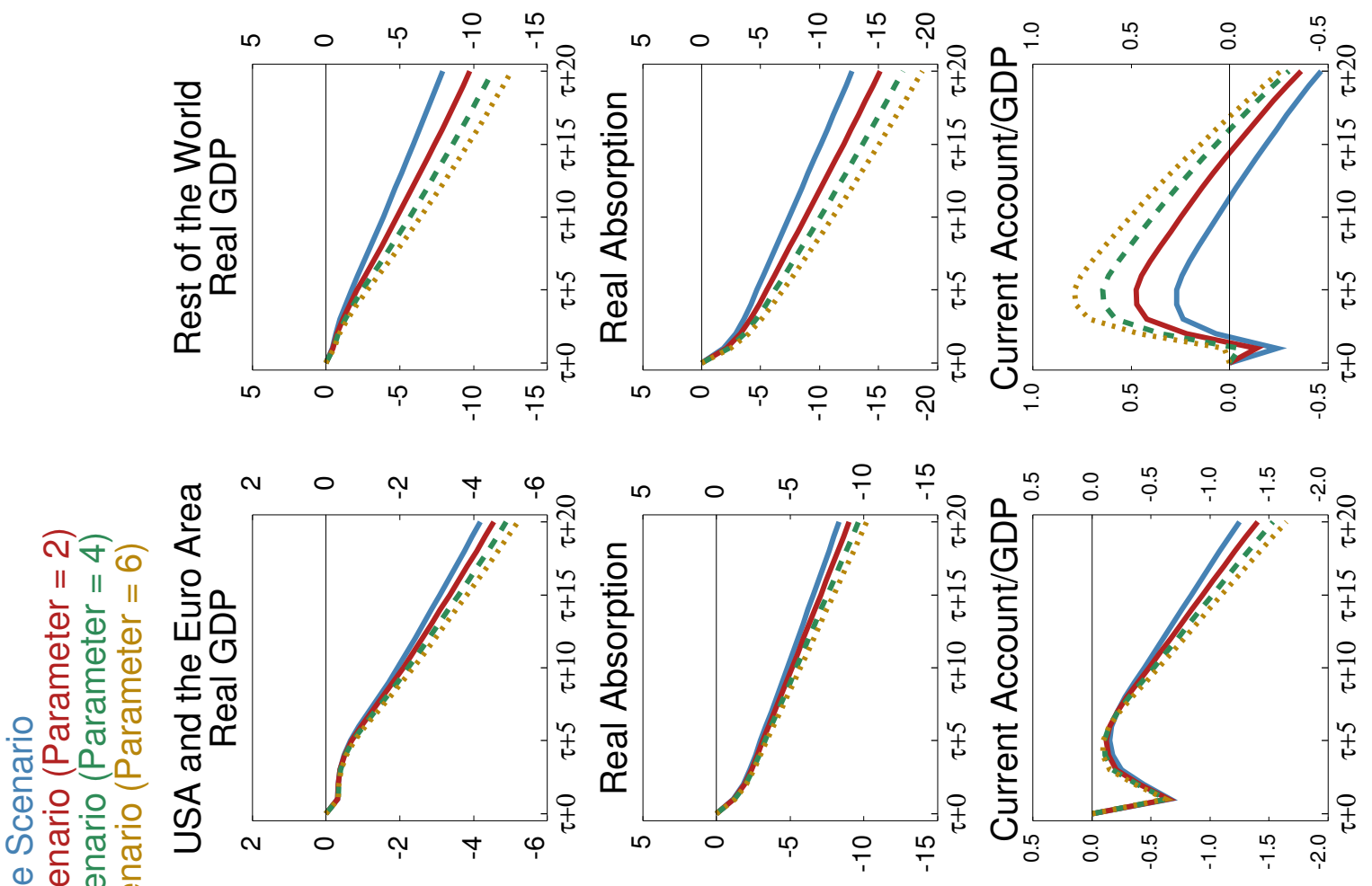
零 记 焉 $\frac{\varpi}{\square} \frac{\widetilde{v}}{\square}$ 옹을
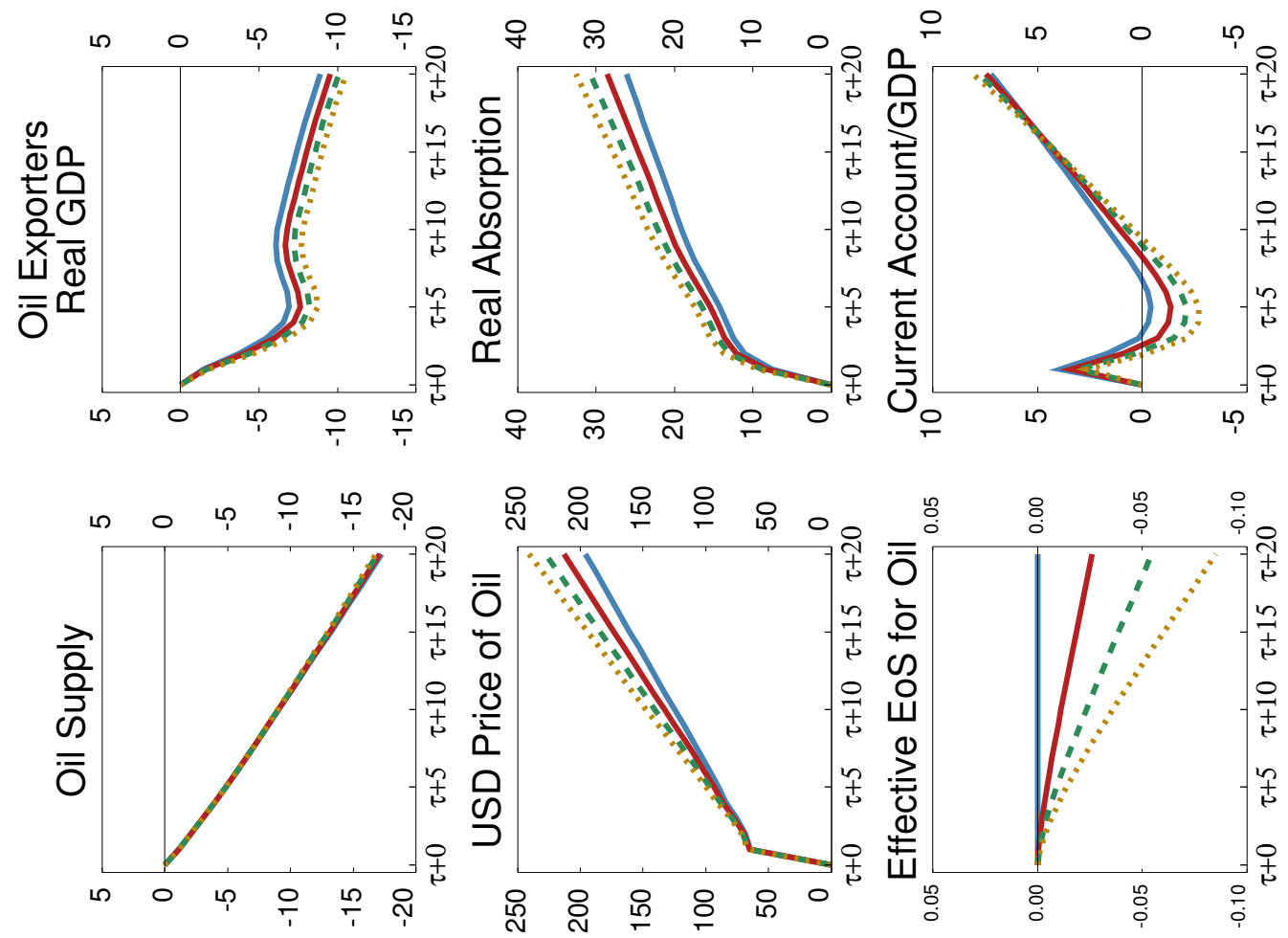
Figure 7. Technology Externality and Larger Shock Scenarios

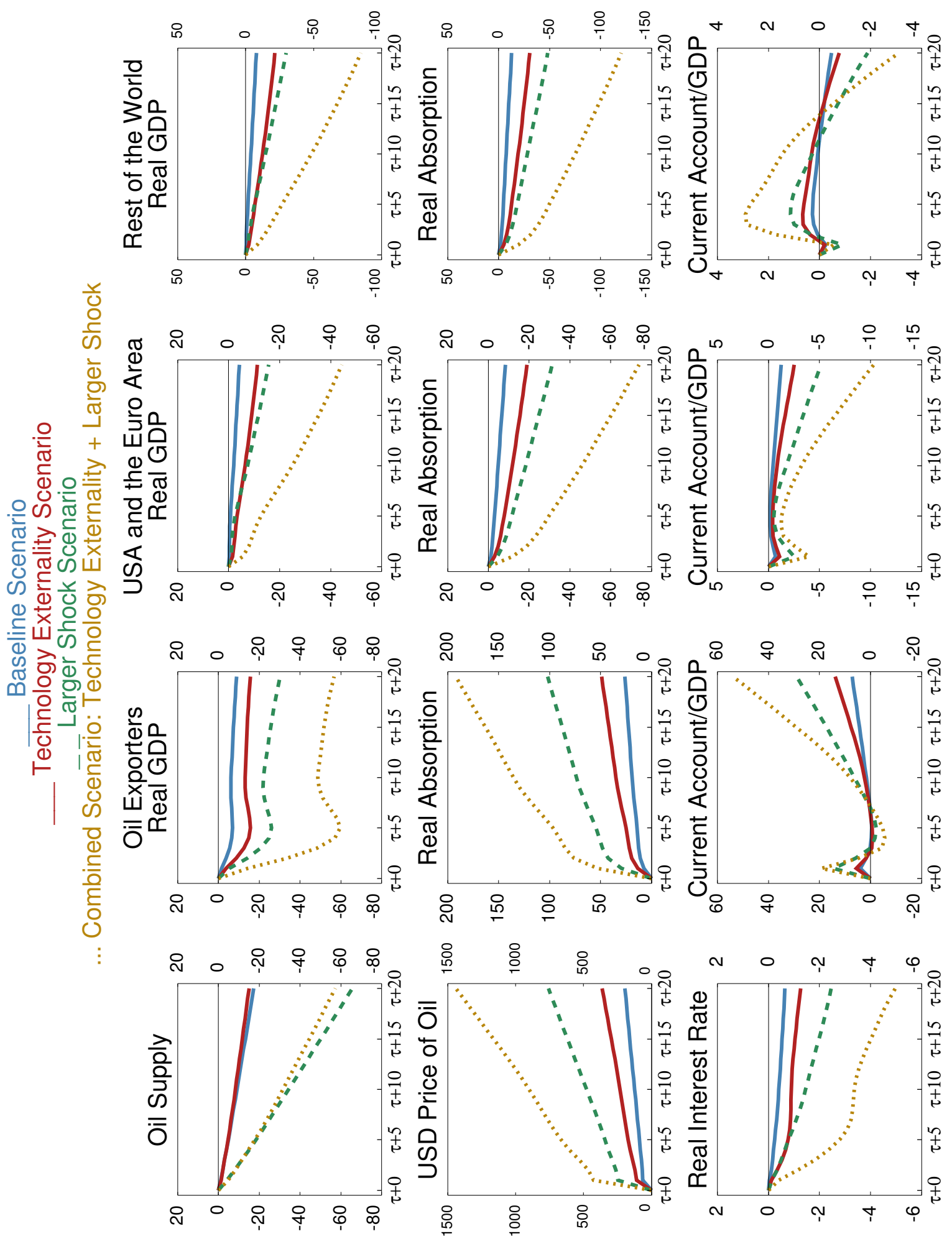


Figure 8. Combined Downside and Growing Elasticity Scenario

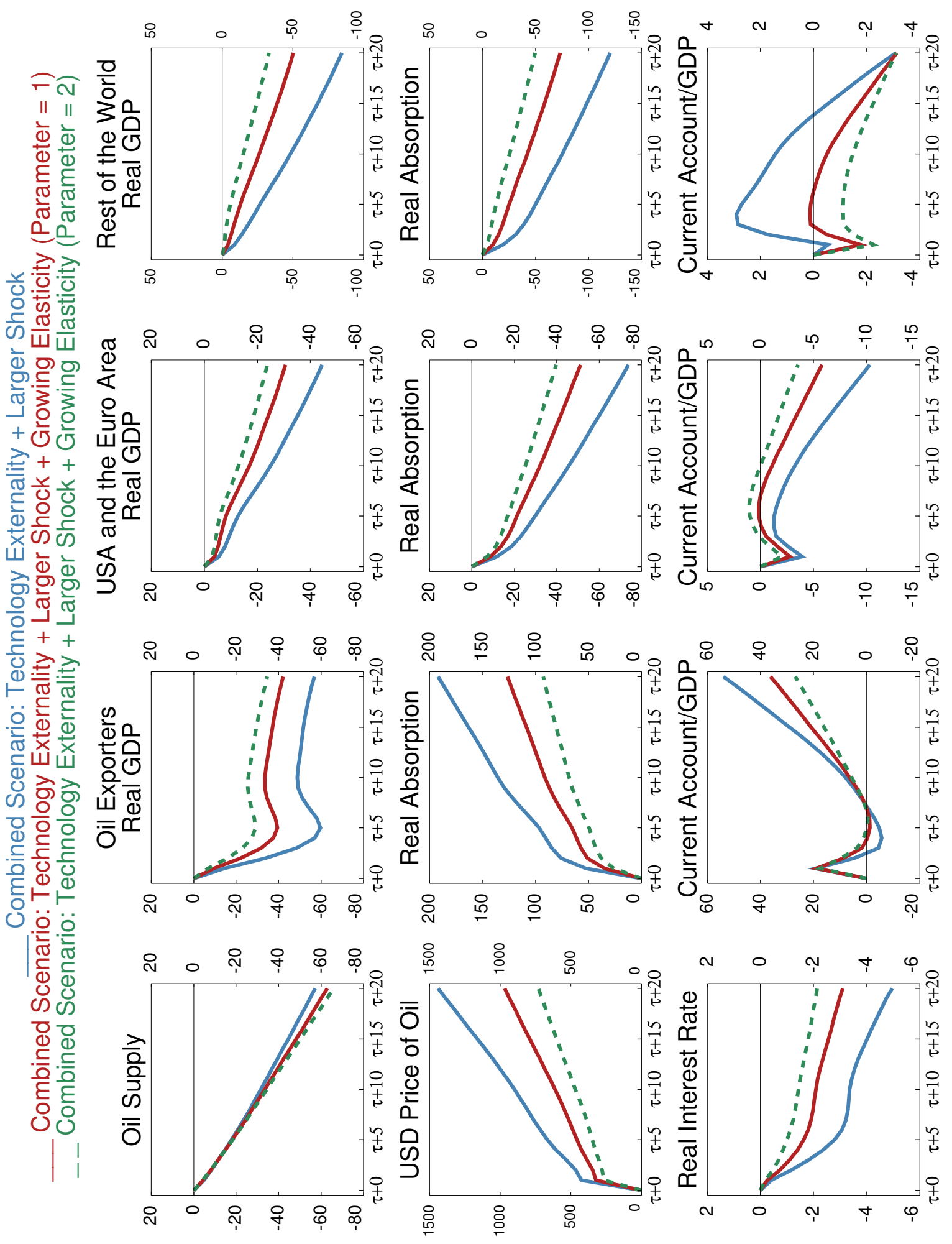

